\title{
Rational use of the natural potential of subarctic regions for sustainable territorial development
}

\author{
Vera Kuznetsova*, and Elza Kuznetsova, and Aliya Kushanova \\ Nizhnevartovsk state University, Lenina Str., 56, 628605 Nizhnevartovsk, Russia
}

\begin{abstract}
The issues of food security and sustainable development of territories are of particular relevance nowadays. From this perspective, analyzing the sustainable use of the natural potential of regions is a priority for the global scientific community. The challenges of improving food security and achieving sustainable territorial development in the subarctic regions are particularly significant against the backdrop of ongoing changes in the natural and climatic conditions. Sustainable development of the subarctic regions requires the sustainable use of natural resources, preservation of natural potential, access to natural and cultural treasures, and consideration of the interests and opinions of the population and businesses in the planning of the social and economic development of the territories. This paper presents a plan for the establishment of a peasant (farm) enterprise located in the subarctic region. The profitability of the peasant (farm) enterprise in question was $18 \%$, with a payback period of 5.5 years. The results of the study can be used in the implementation of regional SME development programmes.
\end{abstract}

\section{Introduction}

One of the major scientific problems of our time is the identification of patterns, description and prediction of the consequences of environmental change under the current conditions of climate change in the subarctic territories. The analysis of these impacts on naturaleconomic systems and the socio-economic processes of the population is of high relevance.

In the northern latitudes (subarctic regions), the processes of modern climate change are clearly observed, causing a reaction of the natural environment, which determines the ecological and food security of the territories. Extreme natural phenomena, including those not typical of these places, occur, which, in varying degrees, can negatively affect the quality of land resources, the economy of the region, the daily living activities of the population, and entail adjustments in planning the development of the ecological, economic and territorial systems of the North.

The challenges of analyzing the current climate change processes and the comprehensive impact of natural and climatic factors on the natural and economic systems and socio-economic processes of the subarctic territories are in line with the direction of the strategy for scientific and technological development of the Russian Federation. All this is

* Corresponding author: vera.kuznetsova26@,gmail.com 
necessary to anticipate the development of natural and social processes, to develop adaptation mechanisms, to develop the integration of scientific research and to ensure food security for the sustainable development of the region.

In today's world, these challenges, which aim to explore adaptation strategies in the face of climate change impacts, are being addressed at the international and - to a certain extent national level. There is particular international interest in studying climate change in the Arctic sector and neighbouring northern (subarctic) regions, where the warming processes are clearly visible. As part of the process of globalization of the Arctic, experts have highlighted the urgent areas of research into changes in the socio-economic policies of the Arctic states, which predetermine the need to rethink Arctic environmental management, environmental security and economics in the current context.

International community recognizes that Earth's climate change and its adverse impacts are a shared concern. Anthropogenic activities have significantly increased the concentration of greenhouse gases in the atmosphere, which has amplified the natural greenhouse effect, causing additional warming of the Earth's surface and atmosphere and adverse impacts on natural ecosystems and populations. All of this necessitates a thorough and comprehensive study and generation of new data on current climate change processes and their impact on natural-economic systems and socio-economic conditions at the regional level, especially in vulnerable subarctic latitudes.

According to the results of the atmosphere surface layer monitoring, there has been a warming trend in recent years in various regions of the globe and especially in high latitudes. The issue of climate change and its impact on the pattern of natural processes resulting in changes in natural resource potential becomes important in studying the population adaptation mechanisms and ensuring sustainable development of subarctic territories to ensure ecological and economic balance.

Research must take into account the peculiarities of the socio-economic environment, changing under the influence of the natural and climatic conditions of the North. Thus, spatial planning, urban development zoning and the territory planification in subarctic latitudes must align with environmental protection requirements, in particular the preservation and restoration of the natural environment, sustainable use of natural resources and environmental safety, taking into account the immediate and long-term environmental consequences of contemporary climate change. It is also important to account for the nature of the impact of current climate change and weather patterns on seasonally dependent activities and especially on the agricultural sector of the circumpolar economy.

Current and foreseeable global warming is associated with massive adverse and irreversible consequences for natural and economic systems, with high risks for global and regional food security, livelihood security and sustainable development. According to the Russian Federation's long-term low-emission development strategy until 2050, adapting to climate change entails not only minimizing the complex risks involved but also creating the conditions for realizing the emerging favourable opportunities for increasing agricultural productivity.

The basis for the sustainable development of the subarctic territories is the efficient and rational use of land and resource potential, orientation of industrial development towards resource conservation, integrated processing of raw materials and environmental protection, reconstruction and technological upgrading of extractive and processing industries, use of new resource-saving technologies, addressing social and economic challenges.

The concept of food provisioning of the region population should provide a combination of the development of industrial and agro-industrial production, state promotion of farming and livestock breeding in the North in order to obtain natural products (milk, eggs, meat, potatoes, vegetables) needed to provide the population with food [1]. 
Current changes in natural and climatic conditions of the subarctic regions result in a distinctive reaction in the functioning of the taiga zone landscapes, their seasonal rhythm. The consequences of these processes are changes in the hydrological regime, aggravation of fire hazards and thawing of permafrost, abnormal weather conditions and ecological disasters. A pronounced climate warming in northern latitudes affects the natural resource potential of the region. All these processes affect the development conditions of subarctic regions and it is important to take them into account in order to prevent adverse environmental and economic effects for the purpose of achieving sustainable development of the territories [2].

We have analyzed the functioning of the agro-industrial complex in Nizhnevartovsk district of the Khanty-Mansiysk Autonomous Area -Yugra, which geographically belongs to the subarctic sector. Analyzed agro-industrial complex is represented by peasant farm enterprises (hereinafter referred to as "PFE") and private subsidiary farms. The farms mainly specialize in cattle breeding (cattle and pigs). The study area is classified as a risk farming area. There are no large-scale agricultural enterprises in the district. Most of the district's farms are located near the city of Nizhnevartovsk, as they are oriented towards local residents - the main consumers of the products [3].

The development of the agricultural sector in the study area is limited by unfavourable natural and climatic conditions, an underdeveloped transport infrastructure and the lack of water supply communications on most farms. The flooding regime of the $\mathrm{Ob}$ and Vakh rivers is a major factor in the formation of soils and floodplain vegetation and plays a decisive role in the development of the agricultural sector in the region. Despite all these conditions, the rate of agricultural development in Nizhnevartovsk district does not lag behind the statistical average for Russia [4]. This is facilitated not only by the structure of agricultural sector development itself, but also by the support from the administrative bodies of municipalities within the purpose-oriented programme "Development of small and medium-sized enterprises, agricultural sector and markets of agricultural products, raw materials and foodstuffs in Nizhnevartovsk district", which aims to develop mechanisms for the sustainable development of agricultural sector and agricultural territories and increasing product competitiveness [5]. In this regard, our study on the formation of collective farms in Nizhnevartovsk district is in line with the objectives of this target programme.

Agricultural production in Nizhnevartovsk district is represented by crop production, which is based on growing vegetables and haying. The livestock complex includes milk and meat cattle breeding. Traditional farming - breeding of cage-raised fur bearing animals - is also in place. Fishing, fish farming and fish processing are well developed. In addition, there is the development of hunting and gathering and processing of wild-growing herbs. All this is in line with the priority municipal programmes for the development of small and medium-sized enterprises, agro-industrial sector and markets for agricultural products, raw materials and food [6].

\section{Materials and Methods}

The study was conducted in accordance with the methodology for assessing the economic efficiency and competitiveness of a newly formed agricultural enterprise.

Agricultural land in the Nizhnevartovsk district consists of arable land, hayfields and pastures. The arable land includes garden and vegetable plots. The pastures, due to the prolonged flooding period and marshiness of the area, are meadowed and used as hayfields. The floodplains of the Ob, Vakh and Bolshoy Yugan rivers account for most of the hayfields in the Nizhnevartovsk district (Figure 1). Field studies were conducted from 2012 to 2020 to determine hay yields, which averaged $35 \mathrm{dt} / \mathrm{ha}$ in hay and $122 \mathrm{dt} / \mathrm{ha}$ in $\mathrm{fresh}$ yield, with fertile soil thickness of $35 \mathrm{~cm}$ [7]. 


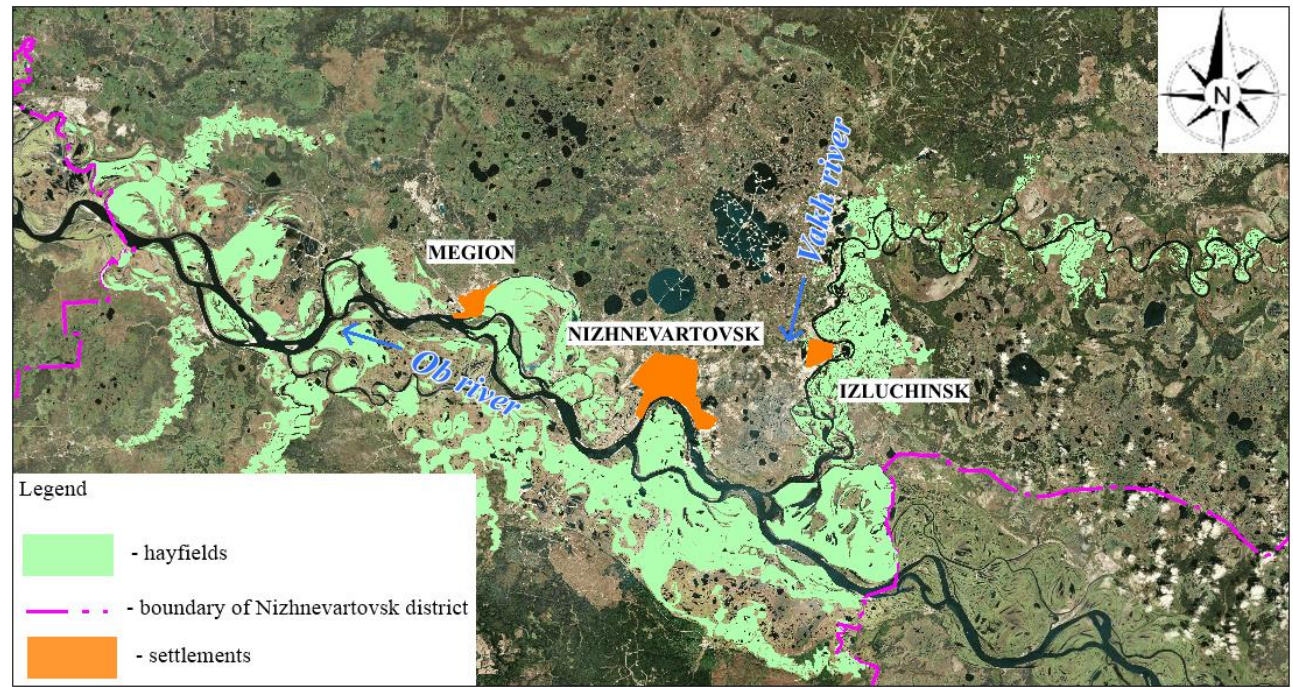

Fig. 1. Hayfields in the floodplains of the $\mathrm{Ob}$ and Vakh rivers (Nizhnevartovsk district, KhantyMansiysk Autonomous Area - Yugra) (compiled by the authors).

The proposed land plot is located within the borders of Nizhnevartovsk district in the floodplain of the Vakh river, near the township of Izluchinsk. To the east of this area is the Savkinski Pasol creek. The city of Nizhnevartovsk is $20 \mathrm{~km}$ from the study area. Urban settlement of Izluchinsk is located $8.5 \mathrm{~km}$ to the north-east (Figure 2). The 58.1 ha of land use consists of two strip farming parcels. The main plot of 57.1 hectares under the PFE is occupied by floodplain hayfields. The PFE farm center will be located on an area of 1 hectare of tree and shrubbery vegetation.

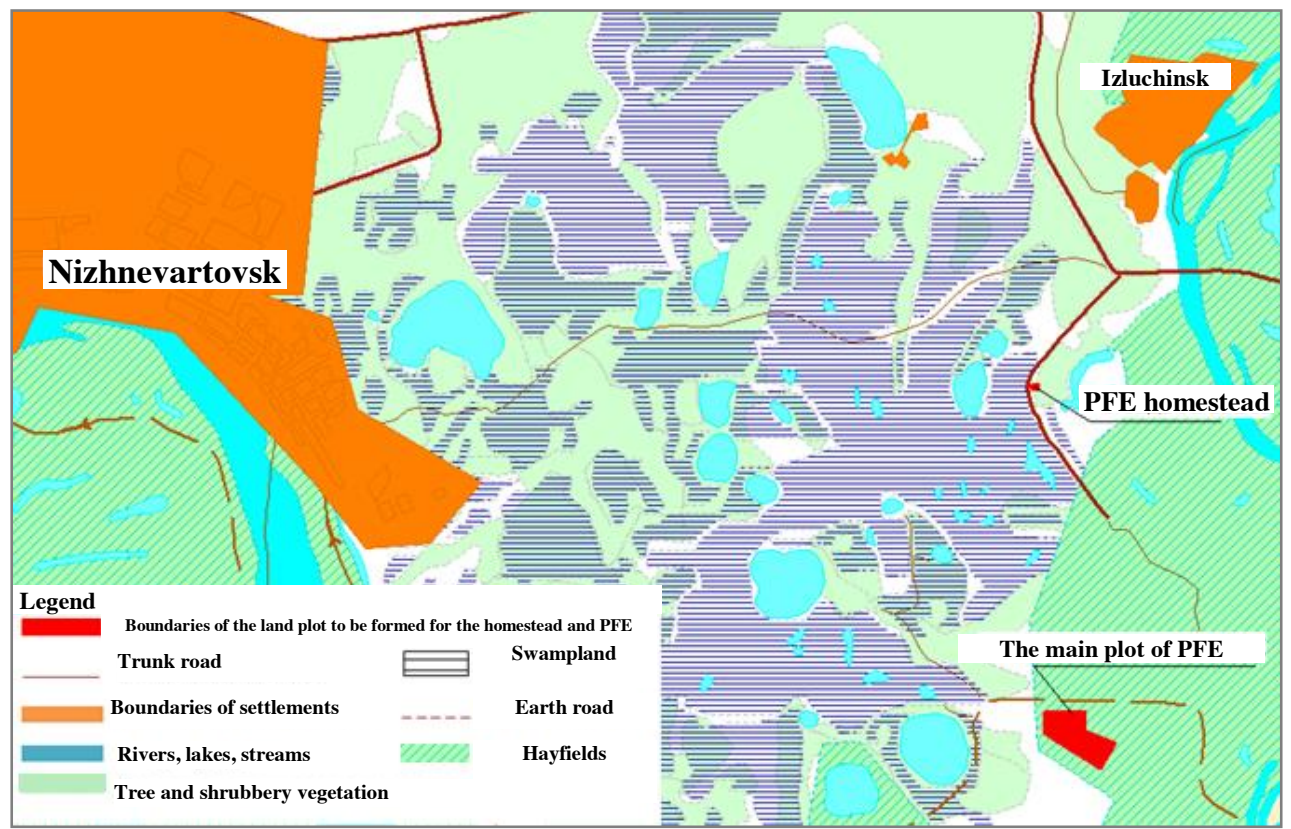

Fig. 2. Land use arrangement for a peasant (farm) enterprise in the territory of Nizhnevartovsk district (compiled by the authors). 


\section{Results and Discussion}

The PFE farmstead will be located on an strip farming land plot, without affecting the water protection area of the Vakh river, in the part occupied by tree and shrubbery vegetation, which will contribute to the rational use of the entire area of agricultural land. The farmstead is designed to have a farm centre that will be located next to the road, making it easy to sell products and deliver the necessary materials and fodder.

The characteristic and assessment of the area for the PFE homestead is given in accordance with SP 42.13330.2016 "Urban development. Urban and rural planning and development". According to the assessment, the probability of groundwater flooding in the area is $50 \%$, the depth of groundwater is $0.9-1.5 \mathrm{~m}$ and surface water is close to the land use area. The analysis revealed that the engineering and geological conditions for locating the farmstead are not favourable, as groundwater is close to the surface and there is a high probability of flooding by high water. To improve conditions in the vicinity of the homestead site, the area should be banked up and drainage systems should be designed.

The analysis of the agro-industrial complex of the Nizhnevartovsk district has revealed that the development of milk and meat cattle breeding in the PFE is quite feasible. The business plan cost-benefit analysis for the PFE being formed showed that 27 cattle and 2 horses need to be purchased at the initial stage. Based on these data, the area for the economic centre has been calculated according to the space requirements per design unit, which will be located on an strip farming land plot. The area of the economic centre is 1 hectare.

In the course of the works, the production volumes of agricultural products necessary for farming, namely concentrated, roughage and succulent fodder, have been defined. Total dietary requirements have been calculated. The results of calculations are presented in Table 1 .

Table 1. Calculation of dietary requirement (dt)

\begin{tabular}{|c|c|c|c|c|c|c|c|}
\hline $\begin{array}{c}\text { Type of } \\
\text { industry }\end{array}$ & Livestock & Concentrated & Roughage & Silage & Haylage & Root crop & Soilage \\
\hline Cattle & 27 & 162 & 108 & 335 & 48.5 & 135 & 783 \\
\hline Horses & 2 & 11 & 6 & 8 & 12 & - & 84 \\
\hline $\begin{array}{c}\text { Security } \\
\text { reserve }\end{array}$ & 26 & 17 & 51.5 & 9 & 20 & 130 \\
\hline Total & & 199 & 131 & 394.5 & 69.5 & 155 & 997 \\
\hline
\end{tabular}

Based on the results of the calculation of the dietary requirement, we made calculations for the area of forage land. These calculations are shown in Table 2.

Table 2. Calculation of forage land area

\begin{tabular}{|l|c|c|c|}
\hline $\begin{array}{c}\text { Type of feed } \\
\text { (due to floodplain hayfields) }\end{array}$ & $\begin{array}{c}\text { Dietary } \\
\text { requirement, dt }\end{array}$ & $\begin{array}{c}\text { Yield, dt/ha } \\
\text { (according to 2020 } \\
\text { data) }\end{array}$ & Area, ha \\
\hline Soilage & 997.0 & 23.7 & 42.0 \\
\hline Hay & 131.0 & 12.6 & 10.4 \\
\hline Silage & 394.5 & 100.0 & 3.9 \\
\hline Haylage & 69.5 & 80.0 & 0.8 \\
\hline Total & & & 57.1 \\
\hline
\end{tabular}

In order to ensure sustainable development and for the rational use of the land and resource potential of the territory, the PFE flooded hayfields will provide roughage, haylage, silage and green fodder. Concentrated feed and root vegetables are purchased from nearby agricultural producers. 
Agricultural products produced by the PFE, namely cattle milk and meat, will be sold in the city of Nizhnevartovsk and the neighbouring settlements.

Livestock and fodder must be purchased to ensure farm operation. Purchase cost calculations are presented in Table 3.

Table 3. Calculation of costs for the purchase of livestock and feed

\begin{tabular}{|c|c|c|c|}
\hline Name & Required quantity & $\begin{array}{c}\text { Price per unit, } \\
\text { RUB }\end{array}$ & $\begin{array}{l}\text { Total amount, } \\
\text { RUB ths }\end{array}$ \\
\hline \multicolumn{4}{|c|}{ Livestock } \\
\hline Feeder bull calf (heads) & 13 & 35,000 & 455 \\
\hline Dairy cow (heads) & 12 & 45,000 & 540 \\
\hline Bull (heads) & 2 & 45,000 & 90 \\
\hline $\begin{array}{l}\text { Total cost of the purchase of } \\
\text { cattle }\end{array}$ & & & 1,085 \\
\hline Horse (heads) & 2 & 30,000 & 60 \\
\hline Total & & & 1,145 \\
\hline \multicolumn{4}{|c|}{ Feed } \\
\hline Concentrated feed $(\mathrm{kg})$ & 19,900 & 11 & 217 \\
\hline Potato $(\mathrm{kg})$ & 15,500 & 12 & 183 \\
\hline Total & & & 400 \\
\hline Total costs & & & 1,545 \\
\hline
\end{tabular}

In the course of the study, an investment budget was made to calculate the cost, which is presented in Table 4.

Table 4. Investment budget

\begin{tabular}{|l|c|c|}
\hline \multicolumn{1}{|c|}{ Name of item of expenses } & $\begin{array}{c}\text { Subsidy } \\
\text { RUB ths }\end{array}$ & $\begin{array}{c}\text { Own funds } \\
\text { RUB ths }\end{array}$ \\
\hline Costs for the land plot reclamation & & 100,000 \\
\hline Construction materials & & \\
\hline - Roof & 250 & \\
\hline - Brick & 150 & \\
\hline - Timber & 50 & 60 \\
\hline Placement of utility lines & 50 & \\
\hline Purchase of young cattle (27 heads) & & 100 \\
\hline Purchase of horses (2 heads) & & 70 \\
\hline Purchase of feed & 400 & 1,415 \\
\hline Milking machine & & \\
\hline Other expenses & & \\
\hline Total & 900 & \\
\hline
\end{tabular}

It is planned to receive a subsidy through participation in one of the municipal programmes "Development of small and medium-sized enterprises, agricultural sector and markets of agricultural products, raw materials and foodstuffs in Nizhnevartovsk district". The amount of capital investments will be 2,315 thousand rubles, including own investments $-1,415$ thousand rubles.

The average daily milk yield per cow reaches 15 litres of milk, and annual milk yield is 4,000 litres. The planned annual income is up to 960,000 rubles.

Up to $4,160 \mathrm{~kg}$ of clean meat per year are planned, with a slaughter yield of $55-60 \%$. Thus, the income from the sale of meat will be 873 thousand rubles.

Based on the analysis, it has been established that the expected income of PFE by 2020 is about 1,833 thousand rubles. Production costs include: labour costs and insurance premiums, utilities, costs of service contracts, transport costs, land plot rent, other 
contingencies [8]. Four people will be employed by the PFE. Their salary costs will be about 576,000 rubles per year and insurance contributions will be 120,000 rubles.

The rest of the work to ensure the PFE operation will be carried out by the members of the farm. The additional cost of a fee-for-service agreement will be 240 thousand rubles per year [9]. Utilities and transport costs will be 456 thousand rubles. Other expenses amount to 120 thousand rubles.

The data obtained show that the PFE production costs will be 1,512 thousand rubles per year. The calculation of the profitability of the PFE being formed showed that this production is efficient and amounts to $18 \%$, with a payback period of 5.5 years.

The results of the study can be used in the implementation of regional SME development programmes. According to the Food Security Doctrine, an analysis of the use of the natural potential of the subarctic regions is necessary for the development of the agro-industrial complex and markets for agricultural products, raw materials and foodstuffs in the regions.

\section{Conclusions}

The natural conditions of the subarctic regions are unfavourable for the development of agribusiness. Natural hayfields in the Nizhnevartovsk district are located in areas that are difficult to access. Flood water levels and duration have a significant impact on the productivity of forage land in the district. In this regard, the yield of hayfields in the study area is quite high, compared with the average indicator for the Russian Federation. During the design of agro-engineering and hydro-technical measures, it is possible to use these lands in agriculture as highly productive ones. In spite of the above-mentioned shortcomings in land use, hayfields are used in agriculture.

The projected land use for the PFE is located in the territory of Nizhnevartovsk district, near the township of Izluchinsk and is focused on dairy and meat production. The business plan and its analysis show that projected land use is profitable and has a payback period of 5.5 years.

Thus, the development of peasant (farm) enterprise, with medium- and long-term planning of the socio-economic sector, contributes to the sustainable development of the region and increases the food security of the territory. This is in line with the goals of sustainable use of natural potential and the sustainable development priorities of the subarctic regions. The use of the natural potential of the subarctic regions needs to be considered amidst the current climate change in order to be able to adapt to these processes.

\section{References}

1. B.A. Voronin, V.M. Sharapova, Ya.V. Voronina, Agrarian Bulletin of the Urals, 04(146), 92 (2016)

2. V.P. Kuznetsova, Environmental Dynamics and Global Climate Change, 11(1), 24 (2020)

3. I.G. Sychev, State of the Environment and Natural Resources in Nizhnevartovsk and Nizhnevartovsk District in 2003-2005: Overview, 6, 94 (2006)

4. N.A. Perchenko, Bulletin of Novosibirsk State Agrarian University, 2, 22 (2005)

5. B.A. Voronin, N.A. Potekhin, Ya.V. Voronina, Agrarian Bulletin of the Urals, 5, 81 (2015)

6. A.U. Kushanova, S.E. Korkin, Bulletin of Udmurt University, 14 (2015) 
7. V. Kuznetsova, E. Kuznetsova, A. Kushanova, International Multidisciplinary Scientific GeoConference Surveying Geology and Mining. Ecology Management, SGEM, 18(2.3), 393 (2018)

8. O.A. Zubrenkova, O.I. Fedotova, Research Azimuth: Economics and Management, 4(13), 32 (2015)

9. V.I. Kudryashova, Ye.V. Nezhelchenko, Effective Development of Peasant Farms: Conditions, Problems, Directions, 207 (2007) 